\title{
Callus Induction and Organogenesis from Pueraria tuberosa (Roxb. ex Willd.) DC
}

\author{
Bindu T. K.", Sheema Dharmapal P., P. S. Udayan
}

Post Graduate Department of Botany \& Research Centre, Sree Krishna College, Guruvayur, Ariyannur P. O., Thrissur-680102, Kerala, India.

\begin{abstract}
Pueraria tuberosa (Roxb. ex Willd.) DC. is a perennial woody climber, commonly known as Indian Kudzu in English, Vidarikand in Hindi and Vidari in Sanskrit. The tubers are used in different systems of medicine viz. Ayurveda, Folk, Homoeopathy, Siddha, Tibetan and Unani. The present study aims to develop an effective protocol for optimum callus induction and organogenesis in Pueraria tuberosa. Callus cultures were first established by inoculating tender leaf explants in Murashige and Skoog's (MS) medium supplemented with different concentrations of 6-Benzylaminopurine $(0.5,1.0$, 1.5, 2.0, 2.5 and $3.0 \mathrm{mg} . \mathrm{L}-1)$ with 1-Naphthaleneacetic acid (0.5 mg.L-1). Maximum callus induction and shoot organogenesis was observed in MS medium containing 1.5 mg.L-1 BAP with NAA 0.5mg.L-1. Fresh weight of the organogenic greenish granular hard callus was $4.70 \pm 0.10$ gm. Shoot organogenesis was observed after 65 days of culture. Maximum shoot buds developed from callus on MS media augmented with $1.5 \mathrm{mg} . \mathrm{L}-1$ BAP with $0.5 \mathrm{mg} . \mathrm{L}^{-1}$ NAA.
\end{abstract}

Keywords-Pueraria tuberosa, Callus, Leaf explants, Organogenesis.

\section{INTRODUCTION}

Pueraria tuberosa belonging to family Fabaceae is distributed throughout tropical parts of India. It is a large climbing shrub with trifoliate leaves and bluish- purple flowers. Ayurvedic physicians use the tubers for the management of general weakness, fertility disorders and also as anti-ageing, Pandey et al., (1998). The tuberous roots act as a galactagogue, stimulant and emollient, Warrier et al., (1995). Its tubers are rich in isoflavonoids and terpenes with puetubersoanol, and tuberosin, Khan et al., (1996). Puerarin, diadzein, genistein and genistin are the isoflavonoids present in callus cultures of P.tuberosa, Kamlesh et al., (2006). Increased isoflavonoid production was reported by elicitation effect in cell cultures of P.tuberosa, Shaily and Ramawat, (2008). Callus cultures of Pueraria candollei var. mirifica was capable of producing high level of isoflavones like daidzein and genistein consistently, Sudarat and Sanha, (2006). During past decades, interest in isoflavonoids have increased considerably. Isoflavonoids have effective role in treating cancer, postmenopausal symptoms and cardiovascular diseases, Dixon and Ferreira, (2002) ; Nestel P, (2004); Duncun, et al., (2003); Vitrac et al., (2004).

There is a growing demand for plant based drugs due to the presence of biologically active compounds and it is therefore necessary to select, multiply and characterize important medicinal plants for commercial use. Further, in vitro protocols offer scope for multiplication and genetic enhancement of desirable genotypes and in vitro plant cell cultures have been considered to be an important source of secondary metabolites from the plants, Manisha et al., (2012).

\section{MATERIALS AND METHODS}

\subsection{Plant sample and experiment designing}

Young, tender leaves collected from three months old vegetatively propagated plants were first washed in running tap water for 10 minutes and then soaked in soap water for 3 minutes. The leaves were cut into small fragments and then immersed in cefotaxime (200 mg.L-1), tetracycline (200 mg.L-1) and bavistin (15 g.L-1) for 5 minutes. The bavistin treated explants were then washed with double distilled sterile water for five times. These explants were then sterilized by mercuric chloride solution for 3 minutes. After several distilled water wash, 4-5 explants were inoculated into MS (Murashige and Skoog, 1962) media supplemented with $3 \%(\mathrm{w} / \mathrm{v})$ sucrose, $0.2 \%(\mathrm{w} / \mathrm{v})$ clerigel and $1 \mathrm{ml}$ lactic acid taken in petridish. The $\mathrm{pH}$ of the media was adjusted to 5.8 after the addition of various concentrations of BAP and NAA. The culture medium was autoclaved at $121^{\circ} \mathrm{C}, 15 \mathrm{psi}$ pressure for 20 minutes. The media were incubated at $25 \pm 2{ }^{\circ} \mathrm{C}$ under 16 hour photoperiod at a relative humidity of 55 percent with a light intensity of 3000 lux. 
Leaf explants were inoculated into media supplemented with various combinations of $\mathrm{BAP}(0.5,1.0,1.5,2.0,2.5$, 3.0 mg.L-1) with NAA (0.5 mg.L-1). Percentage of callus induction, fresh weight and dry weight of callus, colour and texture of callus and the number of days for callus induction were the different parameters observed and recorded. Subcultures were routinely carried out every 10 days interval into fresh media. Growth of callus on different media compositions after 50 days of inoculation were measured in terms of fresh weight and dry weight. Dry weight of the callus was measured by drying at $60^{\circ} \mathrm{C}$ in a hot air oven to a constant weight.

\subsection{Statistical Analysis}

Experiments were conducted with three replications, having 30 samples each. The effect of various treatments on different growth parameters was measured quantitatively and statistically tested using analysis of variance (ANOVA) using "R-statistics package" version 11.0. The significance of the mean values of various treatments was assessed by Duncan's New Multiple Range Test (DMRT) at $\mathrm{p}<0.05$.

\section{RESULTS}

The combined effect of BAP and NAA on callus induction was studied by culturing leaf explants on MS medium supplemented with various concentrations of $\mathrm{BAP}(0.5,1.0$, 1.5, 2.0, 2.5, $3.0 \mathrm{mg} . \mathrm{L}-1)$ with $0.5 \mathrm{mg} . \mathrm{L}-1$ NAA (Table 1). MS basal media without plant growth regulators were taken as control. The explants failed to establish callus on control media. Various types of callus such as compact, friable and granular were observed in different colours as green, creamy yellow and white. Decrease in percent of response $(60 \%)$ was observed at lower concentration of BAP $(0.5$ mg.L-1) with 0.5 mg.L-1NAA. Organogenesis was not recorded from the white friable callus of this media. The fresh weight and dry weight of the callus of this particular media composition were found to be the lowest among other treatments (Table 2). Creamy yellow friable callus (Fig 1A) initiated within 12 days on media with $1 \mathrm{mg} . \mathrm{L}-$ 1BAP and $0.5 \mathrm{mg} . \mathrm{L}-1 \mathrm{NAA}$ and the fresh weight of callus harvested from this media after fifty days was $1.60 \pm 0.15$ gm. Only 2 shoots were differentiated from this callus after 65 days of culture.

It was observed that the callus growth was best in MS media augmented with $1.5 \mathrm{mg} . \mathrm{L}-1 \mathrm{BAP}$ with $0.5 \mathrm{mg} . \mathrm{L}-1$ NAA. This particular media composition resulted in $84 \%$ callus induction within 7days of inoculation (Table 1). After 50 days of culture, the fresh weight and dry weight of callus at this optimum treatment was $4.70 \pm 0.10$ and $2.43 \pm 0.15 \mathrm{gm}$ respectively. The green granular hard callus (Fig $1 \mathrm{C}$ ) resulted after 50 days of culture showed initiation of buds.
These buds developed into 5-6 shoots after 65 days of culture. At higher concentrations of 2 mg.L-1 BAP with NAA $0.5 \mathrm{mg} . \mathrm{L}-1$, the percentage of callus induction reduced $(80.3 \%)$ and the number of days for callus induction increased to14 days. The green buds which originated from the dark compact callus (Fig $1 \mathrm{E}$ ) of this medium developed into 3-4 shoots after 65 days of culture. During subculture after 50 days, the dark brown regions of this callus were removed to reduce contamination. The shoots elongated to a height of 3-4 cm after 85 days of culture (Fig 1F). Frequent sub culturing was done to enhance the survival rate of the callus.

\section{DISCUSSIONS}

Auxin and cytokinin balance is an important factor in the control of cell division in tissue culture. In the present study, different concentrations of auxin and cytokinin influenced callus production from leaf explants. Highest percent of organogenic green granular hard callus was obtained on leaf explants grown on the medium containing 1.5 mg.L-1BAP and 0.5 mg.L-1NAA (Table 1 and 2). Our results are in line with the interaction effect of NAA and BAP on callus formation of Alstroemeria cv. fuego, Seyyed et al., (2013). The leaf explants produced callus on half strength MS media supplemented with BAP and 2,4-D, Reddy et al., (2011). Maximum induction of callus was observed on a combination of 2.0 mg.L-1 2,4-D and 0.5 mg.L-1 NAA from leaf explants, Manokesh et.al., (2014). Tectona grandis produced compact and fibrous callus on MS media with $0.5 \mathrm{NAA}$ and $1.5 \mathrm{mg}$.L-1 BAP after two weeks of culture, Egodawatta et al., (2014). The colour and nature of callus from Tinospora formanii varied with different concentration of BAP and at higher concentration of BAP with NAA, the number of days taken for callus initiation increased and the percentage of response decreased, Sheema et al., (2017) which is in conformity with the results of the present study.

Callus is an important source for indirect plant organogenesis and embryogenesis, two most striking processes in plant micropropagation, Te-chato et al., (2006). It is evident from the results that, among the growth regulators tested, $1.5 \mathrm{mg} . \mathrm{L}-1 \mathrm{BAP}$ with $0.5 \mathrm{mg}$.L-1NAA induced maximum frequency of shoot regeneration with maximum number of leaves. These results are in conformity with those of Manokesh et al., (2014). Genotypes, explant source, physiological status of the donor plants, the culture medium, and the interactions between them are the factors that influence responses like callus induction and regeneration capacity, Ozgen et al., (1996). In the present experiment, high concentrations of cytokinin (1.5 and 2 
mg.L-1) along with very low concentration of auxin promoted shoot regeneration from callus. Our findings are in line with those of Ahmad, (1996) and Ahmad and Spoor, (1999). High fresh weight, callus percentage and effective embryogenesis were observed from leaf explants of Sainfoin (Onobrychis sativa) on MS medium supplemented with $2.5 \mathrm{mg} . \mathrm{L}-1 \mathrm{BAP}$ and $0.5 \mathrm{mg} . \mathrm{L}-1 \mathrm{NAA}$, Sedegh et al., (2012).

Table.1: Effect of BAP and NAA on callus induction from leaf explants of P. tuberosa

\begin{tabular}{|c|c|c|c|c|}
\hline \multirow[t]{2}{*}{ Treatments } & \multicolumn{2}{|c|}{ MS+PGR (mg.L' ) } & \multirow{2}{*}{$\begin{array}{l}\% \text { of explants } \\
\text { showing } \\
\text { Callus induction }\end{array}$} & \multirow{2}{*}{$\begin{array}{l}\text { Number of days } \\
\text { for } \\
\text { callus induction }\end{array}$} \\
\hline & BAP & NAA & & \\
\hline $\mathrm{T}_{0}$ & 0.0 & 0.0 & $0.00^{\mathrm{g}}$ & $0.00^{\mathrm{g}}$ \\
\hline $\mathrm{T}_{1}$ & 0.5 & 0.5 & $60.47 \pm 1.29^{f}$ & $16.20 \pm 0.30^{\mathrm{c}}$ \\
\hline $\mathrm{T}_{2}$ & 1.0 & 0.5 & $65.87 \pm 0.61^{\mathrm{e}}$ & $12.50 \pm 0.10^{\mathrm{e}}$ \\
\hline $\mathrm{T}_{3}$ & 1.5 & 0.5 & $84.26 \pm 0.21^{\mathrm{a}}$ & $07.06 \pm 0.06^{\mathrm{f}}$ \\
\hline $\mathrm{T}_{4}$ & 2.0 & 0.5 & $80.33 \pm 0.15^{\mathrm{b}}$ & $14.41 \pm 0.10^{\mathrm{d}}$ \\
\hline $\mathrm{T}_{5}$ & 2.5 & 0.5 & $72.90 \pm 0.20^{c}$ & $18.35 \pm 0.19^{b}$ \\
\hline $\mathrm{T}_{6}$ & 3.0 & 0.5 & $68.23 \pm 0.25^{\mathrm{d}}$ & $21.30 \pm 0.26^{\mathrm{a}}$ \\
\hline
\end{tabular}

Note: Level of significance was measured at $\mathrm{p}<0.05$. Column values with same superscript are not differing significantly $(\mathrm{P}>0.05)$.

Table.2: Weight of callus and types of callus on different BAP and NAA combinations of MS

\begin{tabular}{|c|c|l|c|c|}
\hline \multicolumn{2}{|c|}{ MS+PGR (mg.L-1) } & Types of callus & Fresh weight (gm) & \\
\cline { 1 - 3 } BAP & NAA & & $0.46 \pm 0.05^{\mathrm{d}}$ & $0.24 \pm 0.02^{\mathrm{d}}$ \\
\hline 0.5 & 0.5 & White friable & $1.60 \pm 0.15^{\mathrm{c}}$ & $0.71 \pm 0.02^{\mathrm{c}}$ \\
\hline 1.0 & 0.5 & Creamy yellow friable & $4.70 \pm 0.10^{\mathrm{a}}$ & $2.43 \pm 0.15^{\mathrm{a}}$ \\
\hline 1.5 & 0.5 & Green granular hard & $3.33 \pm 0.21^{\mathrm{b}}$ & $1.33 \pm 0.15^{\mathrm{b}}$ \\
\hline
\end{tabular}

Note: Level of significance was measured at $\mathrm{p}<0.05$. Column values with same superscript are not differing significantly $(\mathrm{P}>0.05)$. 

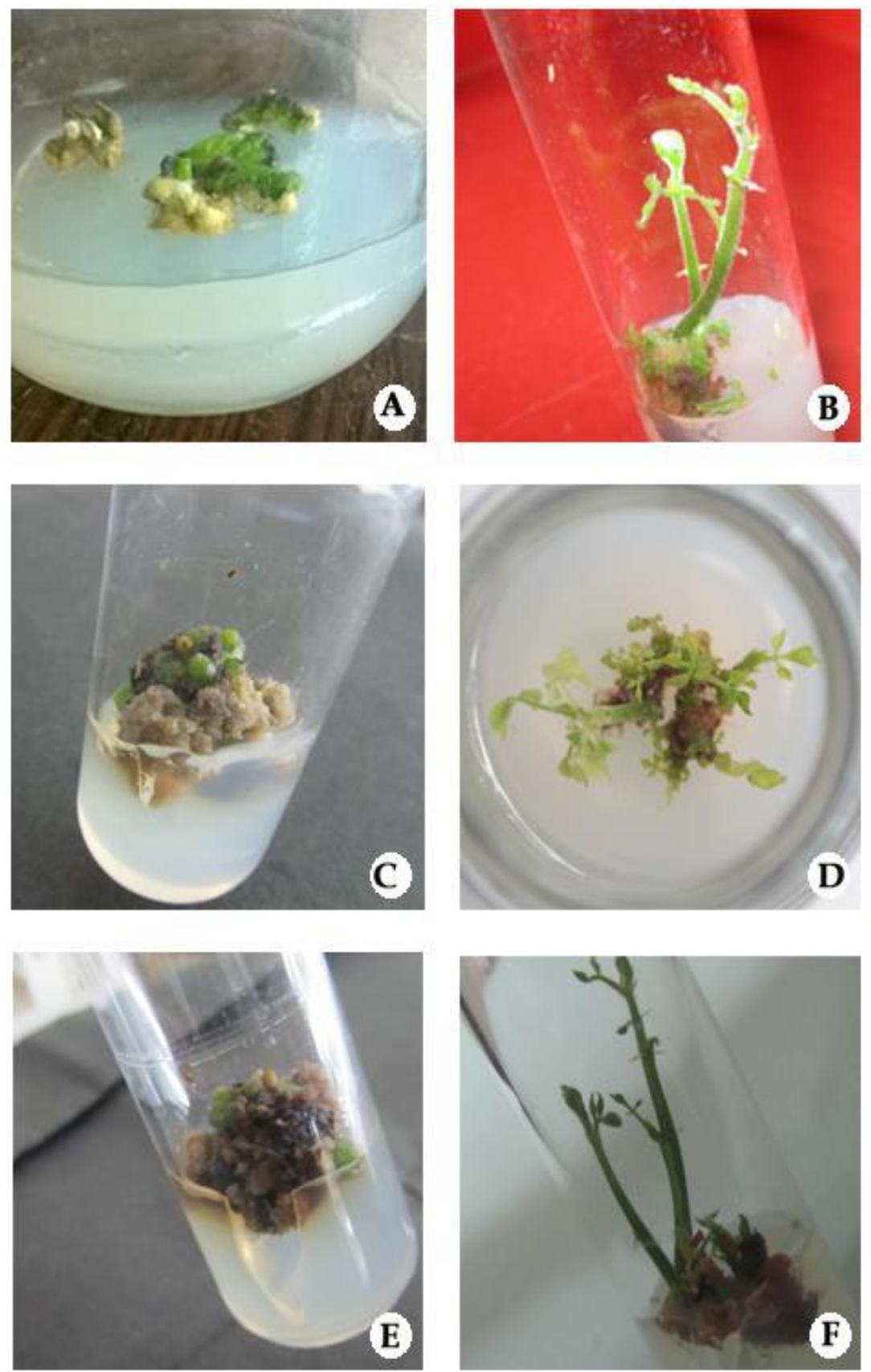

Figure 1. Callus development Organogenesis from leaf explants of Puerarta tuberosa.

A. Callus proliferation on MS medium with $1 \mathrm{mg} \cdot \mathrm{L}-1$ BAP $+0.5 \mathrm{mg} \cdot \mathrm{L}-1 \mathrm{NAA}$;

B. Shoot development from callus on MS with $1 \mathrm{mg} \cdot \mathrm{L}-1$ BAP + $0.5 \mathrm{mg} \cdot \mathrm{L}-1$ NAA;

C. Green granular hard callus; D. Organogenesis from callus on MS with $1.5 \mathrm{mg} . \mathrm{L}-1$ BAP + $0.5 \mathrm{mg} \cdot \mathrm{L}-1$ NAA;

E. Dark compact callus; F. Organogenesis from callus on MS with 2 mg.L- 1 BAP + 0.5 mg.L-1 NAA.

\section{CONCLUSION}

The success of in vitro protocols depends on factors like type of explants and plant growth regulators. In the present study, the effect of different concentrations of BAP with NAA on callus formation and organogenesis of $P$. tuberosa was evaluated using leaf explants. We have 
developed a simple and robust procedure to regenerate this important taxon with the use of BAP and NAA. The present protocol can also be applied for the mass multiplication and secondary metabolite production from the callus without harvesting the whole plant.

\section{ACKNOWLEDGEMENTS}

The authors are thankful to Dr. G. Jayakrishnan, Head of the Department of Botany, Sree Krishna College, Guruvayur for providing all the necessary facilities and encouragement during the work.

\section{REFERENCES}

[1] Ahmad, S. and Spoor, W. 1999. Effects of NAA and BAP on Callus Culture and Plant Regeneration in Curly Kale (Brassica oleracea L.), Pak J Biol Sci. 2: 109-112.

[2] Ahmad, S. 1996. In vitro callus selection in Brassica species. Ph.D.Thesis, Institute of Ecology and Resource Management, University of Edinburgh, UK.

[3] Dixon, R. A. and Ferreira, D. 2002. Molecules of interest, Geneistein. Phytochemistry, 60: 205.

[4] Duncan, A. M., Phipps, W. R. and Kurzer, M. S. 2003. Phyto-estrogens; Best Practice and research. Clin Endocrinol. Metab., 17(2): 253.

[5] Egodawatta, W.C.P., Karunaratne, M.LW.O.M. and Peries, S.E. 2014. Callus Induction and Organogenesis from leaf explants of Tectona grandis. Annals of Biological Research, 5 (4): 74-82.

[6] Kamlesh, V., Shaily G. and Ramawat, K. G. 2006. Isoflavonoids production in callus culture of Pueraria tuberosa, the Indian Kudzu. Indian J Exp Biol. 44: 1012-1017.

[7] Khan, R. A., Agarwal, P.K. and Kapil, R. S. 1996. Puetuberosanol an epoxychalcanol from Pueraria tuberosa. Phytochemistry, 42: 42-44.

[8] Manisha, M., Arun, S., Anupam, K. M., Subhash, K., Ashok, C. and Ashok, D. 2012. Biotechnological advances in overview of present status and future prospects, Vegetos 25: 182-191.

[9] Monokesh, K. S., Shamima, N., Shahedur, R. and Abu Hena, M. J. 2014. In vitro callus induction and plantlet regeneration of Achyranthes aspera L., a high value medicinal plant. Asian Pac J Trop Biomed, 4(1): 40-46.

[10] Murashige, T. and Skoog, F. 1962. A revised medium for rapid growth and bioassays with tobacco tissue cultures. Plant Physiol, 15: 473-497.
[11] Nestel, P. 2004. Isoflavones: Effect on cardiovascular risk and functions, International Congress Series, 1262, 317.

[12] Ozgen, M., Türet, M., Ozcan, S. and Sancak, C. 1996. Callus induction and plant regeneration from immature and mature embryos of winter durum wheat genotypes. Plant Breeding, 115 (6): 455-458.

[13] Pandey, G.S., Chunekar, K.C. and Vidari, K.1998. Bhav Prakash Nighantu. : Chaukambha Vidya Bhavan Varanasi Vol. 1 : pp. 388-9.

[14] Reddy, J. H., Bopaiah, A.K. and Abhilash, M. 2011. Asian J Pharma Health Sci, 1 (2): 70-74.

[15] Sadegh, M., Rosna, M.T., Arash, K. and Jamilah, S.Y. 2012. Induction of different types of callus and somatic embryogenesis in various explants of Sainfoin (Onobrychis sativa), Astralian J of Crop Science. 6(8): 1305-1313.

[16] Seyyed, R. S., Behzad, K., Naghi, P. D. and Ali, S. 2013. Callus induction in Alstroemeria using NAA and BAP. Euro J Exp Bio, 3(5): 137-140.

[17] Shaily, G. and Ramawat, K. G. 2008. Increased isoflavonoids accumulation in cell suspension culture of Pueraria tuberosa by elicitors. Indian $J$ Biotechnol., 7: 378-382.

[18] Sheema, D. P., Najla, M., Swetha, E. S., Udayan, P. S. and Elyas, K. K. 2017. Callus induction and organogenesis from Tinospora formanii Udayan and Pradeep: A rare endemic plant. J Tropical Plant Research, 4(1): 71-76.

[19] Sudarat, T. and Sanha, P. 2006. Production of isoflavones, daidzein and genistein in callus cultures of Pueraria candollei Wall. ex Benth.var. mirifica. Songklanakarin J Sci Technol, 28 (Suppl. 1): 45-53.

[20] Te-chato, S., Susanon, T. and Sontikun, Y. 2006. Cultivar, explant type and culture medium influencing embryogenesis and organogenesis in Anthurium spp. J Sci Technol, 28(4): 717-722.

[21] Vitrac, X., Krissa , S., Decendit, A., Deffieux ,G. and Merillon, J. M. 2004. Grape vine polyphenols and their biological effects, in Biotechnology; Medicinal plant, edited by Ramawat (Sci Pub. Enfield, USA).

[22] Warrier, P. K., Nambiar, V. P. K. and Ramankutty, C. 1995. Indian medicinal plants, A compendium of 500 species, Vols.1-5. Orient Longman Ltd., 160, Anna Salai, Madras. 